\title{
Correlates of Academic Resilience among Secondary School Students in Kiambu County, Kenya
}

\author{
Cecilia N. Mwangi, Anthony M. Ireri and Elizabeth W. Mwaniki \\ Department of Educational Psychology, Kenyatta University, Kenya
}

\begin{abstract}
This study explored how external and internal protective factors combined in predicting academic resilience among secondary school students in Kiambu County, Kenya. The study used a descriptive correlational design. The sample comprised of 390 form three (198 boys; 192 girls) with a mean age of 17 years (SD=1.31; range 12 - 24 years). $A$ demographic form and the California Healthy Kids Survey-Module B, 2007 version were used to collect data. Data were analysed using Pearson's Product Moment Correlation (PPMC) and multiple linear regression. There was a significant strong positive relationship between the external and internal protective factors ( $r(388=.55, p<.05)$. In addition, internal protective factors had a higher positive and significant predictive value on academic resilience $(b=0.42, p<.05)$ than external protective factors $(b=0.29, p<.05)$. The results indicated that internal and external protective factors jointly explained a significant amount of variance in students' academic resilience. A key implication of the findings is that interventions focusing on enhancing internal protective factors while strengthening external factors are more likely to have a better impact in promoting students' academic resilience.
\end{abstract}

Open Access

Citation: Mwangi, C.N., Ireri, A.M., Mwaniki, E.W. (2017). Correlates of Academic Resilience among Secondary School Students in Kiambu County, Kenya. Interdisciplinary Education and Psychology, 1(1):4.

Received: May 12, 2017

Accepted: July 19, 2017

Published: July 25, 2017

Copyright: @ 2017 Mwangi et al. This is an open access article distributed under the terms of the Creative Commons Attribution License, which permits unrestricted use, distribution, and reproduction in any medium, provided the original author and source are credited.

Corresponding author:

Cecilia N. Mwangi, Department of Educational Psychology, Kenyatta University, P.O. Box 43844-00100, Nairobi, Kenya,

E-mail: mwangi.cecilia@ku.ac.ke

\section{Keywords}

Academic resilience; secondary school students; Kiambu county

\section{Introduction}

Stories of individuals who have performed well against all odds abound in different places. An area of interest to parents and stakeholders in education is why some students perform well despite obvious individual and environmental challenges. One possible explanation advanced in research is academic resilience. According to Martin and Marsh (2006), academic resilience is the students' ability to attain positive school outcomes despite academic setbacks, stress, and school-related pressures. Academically resilient students have been found to have good interpersonal skills, confidence in their own ability to learn, positive attitude toward school, pride in their ethnicity, and high expectations (Borman \& Overman, 2004; Garmezy, 1993). Importantly, a resilient student has personal agency, a factor that largely impacts on students' motivation to overcome academic barriers (Solberg, Close, \& Metz, 2002).

To most researchers, resilience is a multifaceted and strengths-based construct that focuses on providing protective factors that enhance success (Schunk \& Zimmerman, 2007). These factors reduce the impact of negative events, help individuals avoid or resist problematic pathways and also promote positive and successful pathways. In literature, the construct of resilience is conceptualized as comprising of intrapersonal resilience factors (internal protective factors) and interpersonal (external) resilience factors. Internal protective factors are mostly personality or dispositional attributes while external protective factors are mainly developmental supports and opportunities (Masten \& Reed, 2002). The complex 
interplay between a student's external and internal protective factors is regarded as the impetus for his or her wellness and success in life (Barr \& Parrett, 2001; Campbell-Sills, Cohan, Stein, 2006; Wasonga, Christman, \& Kilmer, 2003).

An emerging concern in the above conceptualization of resilience is that although the categories of protective factors are universal, their relative importance, the way they are expressed and the way they work to create resilience may differ greatly between cultures (Gunnestad, 2006)). In addition, the definition of a resilient person is likely to differ across cultures. Consistent with this understanding, (Theron \& Malindi, 2013) caution against implementing generic conceptualizations of resilience across contexts and cultures. Other researchers (Didkowsky, Ungar, \& Liebenberg, 2010; Ungar \& Liebenberg, 2011) also argue that the understanding of resilience in specific cultural contexts should be informed by the expertise of local people.

In the USA, Gross (2011) examined how predictors of academic resilience and outcomes interact with each other from an ecological context. The study involved 167 low-income urban African American adolescents. Data were collected using reports by parents, self-report, and in vivo accounts of the adolescents' daily experience. Using the Optimal Data Analysis statistical procedure, the researcher created a multivariable classification tree model, for predicting academic outcomes. The study found school factors to be the strongest predictor of academic resilience. In addition, individual level characteristics such as academic selfefficacy, and social problem-solving predicted academic resilience. Similar findings have been reported among college students (Merdinger, Hines, Ostering, \& Wyatt, 2005).

In South Africa, a qualitative study by Das-Brailsford (2005) focused on factors that helped a group of poor black youth achieve academic success and demonstrate resilience. The study found family support and good relationships with adult role models as external protective factors that influenced a resilient response. The study further reported goal orientation, strong initiative and motivation and experiencing the self as having a sense of agency as internal protective factors.

It is not always that external and internal factors explain variation in students' academic resilience. In a study by Crawford (2006) among 146 sixth to eleventh grade learners in USA on risk and protective factors related to resilience, it was reported that the combination of the identified factors did not explain a significant amount of variance in the scores of students' resilient functioning. The multiple regression analysis of the individual, family, and external risk variables and overall resilience was not significant.

Despite the crucial role of academic resilience in explaining school outcomes and the contextualized nature of that influence, Theron et al. (2013) lament that there is paucity of studies that explore resilience in various African contexts. To address this concern, this study explored the factors that promote students academic resilience in a Kenyan context. The researchers are convinced that education practice and policy may be enriched through research in academic resilience. The next section presents the problem addressed in the study.

\section{Statement of the Problem}

There is considerable consensus in the academic resilience literature that it is desirable for teachers and teachers to facilitate the development of academic resilience among students (Campbell-Sills et al., 2006; Gross, 2011; Schunk \& Zimmerman, 2007). Despite the many empirical studies investigating academic resilience and its predictive factors globally, research on resilience among secondary school students in Africa is scarce (Theron et al., 2013). Moreover, available studies describe protective factors in isolation, without examining how these factors combine to create academic resilience in an individual (Luther (2006)). To address these gaps, we conducted this study to examine the intercorrelations of resilience protective factors among secondary school students in a Kenyan set up.

A number of studies have examined factors that contribute to variations in academic achievement among secondary school students in Kenya (Gitau, 2005; Gitonga, 1997; Kwena, 2007; Macharia, 2011; Mwangi, Okatcha, Kinai, \& Ireri, 2015; Murugami, 2002; Oliwa, 1998; among others). However, little emphasis has been given to academic resilience. It therefore remains unclear how personal and environmental factors account for academic resilience among students in Kenya. For this reason, this study examined the underlying interactions among multiple protective factors that predict academic resilience. In this regard, we 
hypothesized that there is no significant correlation between external and internal protective factors. It was also hypothesized that the two did not significantly predict academic resilience.

In the next section we present an overview of the theoretical framework that guided the study.

\section{Theoretical Framework}

This study was framed upon the Ecological Systems Theory by Bronfenbrenner (1979). This theory views resilience as an ever-changing product of interacting relationships within a given ecosystemic context. Within the ecological model, resilience is conceptualized as a process embedded in multiple layers: the microsystem, mesosystem, exosystem, macrosystem and chronosystem. Within the microsystems are the student's family, peers, school, and neighborhood that the student interacts with. For Bronfenbrenner (1979), the student is not a passive recipient of experiences in these settings, but someone who reciprocally interacts with others and helps to construct the settings.

The mesosystem involves linkages between microsystems, such as the connections between family and school experiences, and between families and peers. Bronfenbrenner argues that development is likely to be optimized by strong supportive links between microsystems. Nonsupportive links between microsystems can spell trouble. For example, when peers devalue academics, they often undermine an adolescent's scholastic performance, despite the best efforts of parents and teachers to encourage academic achievement. The exosystem is at work when experiences in another setting (in which the student does not have an active role) influence the students and teachers experience in the immediate context e.g. provision of facilities. The chronosystem refersto socio-historicalconditions of students' development, for example, students today are growing up in the electronic bubble of an environment defined by computers and new forms of media. Each social system has its own dynamics, rules, discourses and relationships.

There is a bidirectionality in the relationship between a person and the environment. Thus, secondary school students influence life situations as well as being influenced by them, and their activities can either be supported or blunted by their environments. If students experience a supportive and nurturing family situation and are exposed to positive adult models in the community, then they become more resilient. Conversely, if familial, school, peer and community support remain inadequate and adult role models remain absent or dysfunctional, students are much more likely to become less resilient. According to Bronfenbrenner (1979), the optimal outcome is achieved when all systems are supportive of the individual.

This theory emphasizes a paradigm shift from the traditional approach of focusing on negative attributes or deficits to focusing on students' strengths. It also considers the interaction between the internal and external protective factors that aid in fostering academic resilience. Toland and Carrigan (2011) indicate that resiliency is recognized as an ecological phenomenon shaped by cultural influences and therefore, knowledge and application of resilience is crucial if school psychologists wish to impact students and the cultures they come from. This argument informed the decision to use the ecological framework in this study. Consistent with Toland and Carrigan's view, the authors were convinced that academic resilience cannot be the same for all students globally hence the need to explore the construct in other cultural setups like the Kenyan one.

\section{Materials and Methods}

A descriptive correlational research design was utilized in this study. This design was considered appropriate in this study as it helped to investigate the predictors of academic resilience and how they relate to academic achievement.

\section{Participants}

The study involved 390 secondary school students from 10 schools in Kiambu County, Kenya. The participants were all in form three, the third class of Kenyan secondary school education. The sample was drawn from boys only boarding, girls only boarding, and mixed day secondary schools. The sample size was determined using the Yamane formula (Yamane, 1973) and comprised 198 boys and 192 girls. The participants' mean age was 17 years $(s d=1.31)$ with a range of 12 to 24 years.

\section{Measures}

Data was collected using a students' background questionnaire that was used to solicit for demographic information; and the California Healthy Kids Survey-(Module B) to gather data on a variety of external and internal protective factors associated with academic resilience. It is a likert 
scale developed for the California Department of Education (CDE). In this study, the first five items on the scale were rated on a five point scale, ranging from $1=$ strongly disagree to $5=$ strongly agree. Items 6-56 were rated on a 4-point scale, ranging from $1=$ not at all true to $4=$ very much true. The students were instructed to indicate the degree to which each item in the module applied to them. The minimum possible score in the CHKS was 56 while the maximum possible score was 229. The points were averaged as follows: (i) High resilience: percentage of students with average item response above 172-229; (ii) Moderate: percentage of students with average item response of 114-171; (iii) Low: percentage of students with average item response of 56-113.

Several studies (Elliot \& McGregor, 2001; Hanson \& Kim, 2007; Sharkey, You, \& Schnoebelen, 2008) report adequate construct validity of the scale and provide evidence of its balanced coverage of internal and external protective factors across youth populations from different cultures. Content validity of the questionnaire was enhanced by discussing it with developmental psychology experts and secondary school teachers in Kenya. In the current study, the Cronbach alpha was used to estimate reliability (Mwangi et al., 2015). During piloting, the internal consistency for the six sub-scales was found to be between .93 and .71 with an overall reliability of .87, higher than that of .84 reported by Lucero (2011). The scale was considered sufficiently reliable to warrant the use of the CHKS/RYDM in the Kenyan setting.

\section{Procedure}

Written and informed consent was obtained from the participants prior to questionnaire administration. Confidentiality of research data was assured. The form 3 study participants completed the questionnaire, in the presence of the researcher within a duration of 30-40 minutes. Directions were provided to the students both verbally and in writing. The questionnaire was administered in the classroom setting during the school hours in order to ensure maximum participation by the respondents. Participants were assured that all their responses would remain confidential.

\section{Results}

Results on the correlation between the domains of the external and internal protective factors are shown in Table 1.

Table 1. Intercorrelations among the Domains of the External and Internal Protective Factors

\begin{tabular}{|l|c|c|c|c|c|c|}
\hline \multicolumn{1}{|c|}{ Variable } & 1 & 2 & 3 & 4 & 5 & 6 \\
\hline 1. High Expectations & - & & & & & \\
\hline 2. Caring Relationships & $.74^{* *}$ & - & & & & \\
\hline 3. Meaning Participation & $.53^{* *}$ & $.46^{* *}$ & - & & & \\
\hline 4. Sense of Meaning and Purpose & $.50^{* *}$ & $.42^{* *}$ & $.48^{* *}$ & - & & \\
\hline 5. Autonomy and Sense of Self & $.31^{* *}$ & $.27^{* *}$ & $.40^{* *}$ & $.53^{* *}$ & - & \\
\hline 6. Social Competence & $.10^{* *}$ & .09 & $.24^{* *}$ & $.16^{* *}$ & $.22^{* *}$ & - \\
\hline
\end{tabular}

Note. $N=390 .{ }^{* *} p<.05$ (2-tailed).

The results indicated that the strongest correlation was between high expectations and caring relationships $(r(388)=.74, p<.05)$, followed by high expectations and meaningful participation $(r(388)=.53, p<.05)$ and autonomy and sense of self and sense of meaning and purpose $(r$ $(388)=.53, p<.05)$. The correlation between sense of meaning and purpose and high expectations was moderate $(r(388)=.50, p<.05)$. Relatively weaker correlations were found between social competence and meaningful participation $(r(388)=.24, p<.05)$; social competence and autonomy and sense of self $(r(388)=.22, p<.05)$; as well as between sense of meaning and purpose and social competence $(r(388)=.16, p<.05)$.

Interestingly, the results revealed a weak positive correlation between social competence and high expectations $(r(388)=.10, p<.05)$. There was no significant correlation between social competence and caring relationships $(r(388)=.09, p<.05)$, though positively correlated. A 
significant strong positive relationship was found between the external and internal protective $(r$ $(388=.55, p<.05)$. These results, therefore, did not support our hypothesis.

A multiple regression analysis was conducted to determine whether the internal and external protective factors jointly predicted academic resilience. As presented in Table 2, the results indicated that internal and external protective factors jointly explained a significant amount of variance in students' academic resilience $\left(F=174.15, p<.05 ; R^{2}=.47, R_{\text {Adjusted }}^{2}=.47, S E E=.73\right)$.

Table 2. Model Summary for Prediction of Academic Resilience

\begin{tabular}{|c|c|c|c|c|}
\hline$R$ & Adjusted $R^{2}$ & SEE & $F$ & $P$ \\
\hline .69 & .47 & .73 & 174.15 & .01 \\
\hline
\end{tabular}

Note. $N=390$. SEE = standard error of estimate.

The predictive weights for the internal and external protective factors were as presented in Table 3.

Table 3. ßeta Coefficients for External and Internal Protective Factors

\begin{tabular}{|l|c|c|c|c|}
\hline \multirow{2}{*}{\multicolumn{1}{|c|}{ Model }} & \multicolumn{2}{c|}{$\begin{array}{c}\text { Unstandardized } \\
\text { Coefficients }\end{array}$} & $\begin{array}{c}\text { Standardized } \\
\text { Coefficients }\end{array}$ & \multirow{2}{*}{ Sig. } \\
\cline { 2 - 5 } & $\beta$ & Std. Error & $\beta$ & \\
\hline (Constant) & -3.49 & .19 & & .00 \\
\hline External Protective Factors & 0.01 & .00 & .29 & .00 \\
\hline Internal Protective Factors & 0.04 & .01 & .45 & .00 \\
\hline
\end{tabular}

The results indicated that both internal protective factors and external factors had significant and positive predictive weights on academic resilience. Interestingly, internal protective factors had a higher predictive value on academic resilience $(\beta=.42, p<.05)$ than external protective factors $(\beta=.29, p<.05)$.

From our results, the equation for predicting academic resilience from internal and external protective factors was:

$$
y^{\swarrow}=-3.49+.29 E P F+.42 I P F, R^{2}=.47, F=174.15, p<.05 \ldots \text { (1) }
$$

Note. $\mathrm{Y}=$ academic resilience $(\mathrm{Z}-\mathrm{Score})$; EPF = external protective factors; IPF= internal protective factors.

\section{Discussion}

The findings of the current study indicate that the external and internal protective factors jointly predict academic resilience. These findings add credence to the view by the ecological model of resilience that there is a dynamic interaction among the six protective factors. The strongest correlation was observed between high expectations and caring relationships. This finding is consistent with the results reported by Astudillo (2015) that teachers who held high expectations of their learners and also emphasized the importance of caring classroom relationships were instrumental in the students' academic resilience. The results further corroborate the finding by Lucero (2011) that all the six external and internal protective factors were positively correlated with each other among Latino students at an urban high school in the Los Angeles.

The findings further suggest that protective factors intercorrelate and work symbiotically to facilitate achievement of resilience. This is consistent with the findings reported in a number of other studies (Beka, Daga, Doboro, \& Dominiko, 2014; Gross, 2011; Mampane, 2014; Mehrotra \& Chaddha, 2013; Ratioran \& Phlainoi, 2014; Sanders, 1999; Ungar, 2004). The positively significant correlation between protective factors and resilience could imply that the ability to bounce back in the face of setbacks tends to be high in adolescents who have safe internal and external protective factors.

The findings of this study support the premise that a constellation of external and internal protective factors facilitate students' academic resilience. As noted by Sandoval-Hernández and 
Białowolski (2016) effective resilience requires a combination of both internal and external protective factors. To focus merely on developing one of them is not very effective in rendering students sufficiently academically resilient. The study adds a voice to that of past studies that argue that it is the cumulative effect of multiple protective resilience factors that allows an individual to be successful (Campbell-Sills, Cohan, \& Stein, 2006; Elder \& Conger, 2000; Sandoval-Hernández \& Białowolski, 2016)

This study found that internal protective factors had a stronger positive and significant predictive value on academic resilience than external factors. This finding might offer weight to the assertion by Sandoval-Hernández and Białowolski (2016) that personal protective factors are the most important in predicting resilience. Looked at from the lenses of the ecological model of resilience, it is likely that extrinsic protective factors only offer a supplementary and secondary buffer to challenges. This view is consistent with the conclusion by Rennie and Dolan (2010) that adequate benefits of external protective factors, cannot be realized without the initial base of a resilient personality.

Although the study was done within a Kenyan context, the findings are generally in agreement with previous studies in mainly Western contexts that emphasize the role of personal attributes in enhancing students' academic resilience processes (Foster, 2013; Lee et al., 2013). This may imply the cross-cultural applicability of the ecological model of resilience. It may also imply that teachers, parents and other care givers may benefit learners more if they tailored academic experiences in ways that promote internal protective factors.

\section{Limitations}

The readers should have the following limitations in mind while interpreting the results of the study. First, our study only focused on students' academic resilience at one point in time. In addition, despite the multi dimensionality of resilience, the study focused only on academic resilience. Future studies could focus on the other dimensions of resilience. It should also be noted that data were only collected through a one-time administration of a self-report questionnaire for students. This may have introduced bias in the responses. The use of a longitudinal design as well as multiple tools for measuring academic resilience should be considered in future studies.

\section{Recommendations}

Our findings have important practical implications. First, since both internal protective and external protective factors had significant and positive predictive weights on academic resilience, teachers, parents and other stakeholders should create learning environments that emphasize both types of factors in helping students develop everyday mechanisms for overcoming setbacks. In addition, our results indicated that the internal protective factors were more important in predicting academic resilience than external protective factors. Therefore, efforts aimed at strengthening students' internal factors may be more important in enhancing their academic resilience. However, more research is needed on academic resilience among Kenyan students before a definitive statement can be made on the benefits of promoting internal protective factors more than external protective factors.

Future studies may extend the findings of this study in a number of ways. First, it may be necessary to examine the protective factors at multiple time points to determine their interactions and predictive capacity more conclusively. This may call for future studies to adapt longitudinal designs. Our study only took a snapshot view of students' academic resilience at one point in time. Second, other studies may factor in the other dimensions of resilience such as cognitive, transactional, behavioural, motivational, existential or spiritual as well as relational and emotional resilience. We only focused on academic resilience despite the multi-dimensional nature of the construct. Third, studies may use more robust methods of data analysis such as path analysis, to establish directions of influence between multiple antecedents that predict academic resilience. Fourth, the relationship between academic resilience and academic outcomes needs to be explored in depth among Kenyan students. This could be done by involving samples drawn from all levels of education like primary, colleges and university in all the counties in Kenya. Researchers could also consider using qualitative designs or mixed methods inquiry to get richer accounts of what Kenyans consider to be the qualities of academically resilient students. 


\section{Conclusion}

Looking specifically at the intercorrelations between internal and external protective factors, two conclusions can be drawn in this study. First, both internal and external protective factors significantly predict academic resilience among secondary school students in Kiambu County, Kenya. These factors tend to have transactional interactions in predicting academic resilience. Second, internal protective factors have more weight in predicting academic resilience. This suggests that interventions that seek to enhance internal protective factors while strengthening external factors are likely to have a better impact in fostering students' academic resilience.

\section{Ethical Statement}

This study was done in accordance with set down ethical procedures. The study was approved by the Kenya National Commission for Science Technology and Innovation via Permit no: NACOSTI/P/13/3022/474. Consent was sought from the study participants and due care was taken to ensure that participants identities were not revealed during the study.

\section{Acknowledgements}

We also acknowledge the assistance provided by T. Kiku Annon of WestEd for granting permission to use the Cal_SCHLs CHKS Resilience Items.

\section{Funding}

This work was supported by Kenyatta University through the School of Education Dean's Grant no: WR25129-14.s. 


\section{References}

Alva, S. A. (1991). Academic invulnerability among Mexican-American students: The importance of protective resources and appraisals. Hispanic Journal of Behavioral Sciences, 13(1), 18-34. https://doi.org/10.1177/07399863910131002.

Astudillo, M. (2015). Latino academic resilience: Stories of high achieving middle school ells and the teachers and families that help them succeed. University of Rhode Island. Retrieved from http://digitalcommons.uri.edu/oa_diss.

Barr, R. \& Parrett, W. (2001). Hope fulfilled for at risk and violent youth: K-12 programs that work (2nd ed.), MA: Allyn and Bacon.

Beka, M. B., Daga, E. G., Doboro, E. D., \& Dominiko, T. (2014). Risk factors and resilience: The case of second cycle primary school children in Wolaita Zone, Ethiopia. Journal of Social Science Studies, 1(2), 249. https://doi.org/10.5296/jsss.v1i2.5920.

Borman, G.D. and Overman, L.T. (2004). Academic resilience in mathematcis among poor minority students. Elementary School Journal, 104, (3), 177-195.

Bronfenbrenner, U. (1979). The ecology of human development: Experiments by nature and design. Harvard University Press.

Brooks, J. E. (2006). Strengthening resilience in children and youths: Maximizing opportunities through the schools. Children \& Schools, 28(2), 69-76. https://doi.org/10.1093/cs/28.2.69.

Campbell-Sills, L., Cohan, S. L., \& Stein, M. B. (2006). Relationship of resilience to personality, coping, and psychiatric symptoms in young adults. Behaviour Research and Therapy, 44(4), 585-599. https://doi.org/10.1016/j.brat.2005.05.001.

Carruthers, L. (2007). Integration of cognitive and affective learning: Policy and program considerations for reconstructing schools to support resiliency. Resiliency Reconsidered: Deconstructing the Policy Implications of the Resiliency Movement, 51-67.

Crawford, K. (2006). Risk and protective factors related to resilience in adolescents in an alternative education program. Graduate Theses and Dissertations. Retrieved from http://scholarcommons. usf.edu/etd/2493.

Dass-Brailsford, P. (2005). Exploring resiliency: Academic achievement among disadvantaged Black youth in South Africa. South African Journal of Psychology, 35(3), 574-591.

Didkowsky, N., Ungar, M., \& Liebenberg, L. (2010). Using visual methods to capture embedded processes of resilience for youth across cultures and contexts. Journal of the Canadian Academy of Child and Adolescent Psychiatry, 19(1), 12-18. Retrieved from http://www.cacap-acpea.org /en/cacap/index.php?page=828.

Elder, H. G., \& Conger, D. R. (2000). Children of the land: Adversity and success in rural America. Chicago, IL: University of Chicago Press.

Elliot, A. J., \& McGregor, H. A. (2001). A $2 \times 2$ achievement goal framework. Journal of Personality and Social Psychology. https://doi.org/10.1037/10022-3514.80.3.501.

Esquivel, G., Doll, B.,\& Oades-Sese, G. (2011). Introduction to the special issue: resilience in schools. Psychology in the Schools, 48 (7), 649-651.doi:10.1002/pits.20585.

Finn, J. D., \& Rock, D. A. (1997). Academic success among students at risk for school failure. The Journal of Applied Psychology, 82(2), 221-34. Retrieved from http://www.ncbi.nlm.nih.gov/pubmed/9109280.

Foster, T. A., \& Piedmont College. School of Education. (2013). An exploration of academic resilience among rural students living in poverty.

Fraenkel, J. R., \& Wallen,N. E. (2008). How to design and evaluate research in education (7th ed.). Boston: McGraw- Hill.

Garmezy, N. (1993). Children in poverty: Resiliency despite risk. Psychiatry 56, 127-36.

Gitau, M. M. (2005). Relationship between form four students' achievement moivation, self-efficacy and mathematics performance in Nyandarua District, Kenya. Kenyatta University.

Gitonga, F. M. (1997). A study of absenteeism and the effects on academic achievement among marginalized urban children. Kenyatta University.

Graber, R., Pichon, F., \& Carabine, E. (2015). State of knowledge and future research agendas. Retrieved from www.odi.org. 
Gross, I. M. (2011). Predictors of academic achievement and failure among low-income urban African American adolescents: An ecological perspective. Loyola University Chicago. Retrieved from http://ecommons.luc.edu/luc_theses/498.

Gunnestad, A. (2006). Resilience in a Cross-Cultural Perspective. How resilience is generated in different cultures, Journal of Intercultural Communication, 11(April 2006) available at: http://www.immi. se/intercultural/nr11/gunnestad.htm.

Hanson, T. L., Austin, G., \& Lee-Bayha, J. (2003). Student health risks, resilience, and academic performance: Year 1 report. Health and Human Development Program, WestEd.

Hanson, T. L., \& Kim, J.O. (2007). Measuring resilience and youth development: the psychometric properties of the Healthy Kids Survey. Washington, DC. Retrieved from https://ies.ed.gov/ ncee/edlabs/regions/west/pdf/REL_2007034.pdf.

Henderson, N. (1998). Make resiliency happen. Education Digest, 63(5), 15-19.

Institute of Policy Analysis and Research. (2008). Radical reforms for Kenya's education sector: Implementing policies responsive to vision 2030 (Policy Issue No. 4). Nairobi, Kenya.

Kiswarday, V. (2012). Empowering resilience within the school context. Metodicki Obzori, 7(1), 93-103.

Kwena, J. A. S. (2007). An investigation into selected factors on academic self-concept among primary school pupils in Bondo District. Kenyatta University, Nairobi, Kenya.

Lee, J. H., Nam, S. K., Kim, A.-R., Kim, B., Lee, M. Y., \& Lee, S. M. (2013). Resilience: A meta-analytic approach. Journal of Counseling \& Development, 91(3), 269-279. https://doi.org/10.1002/j.15566676.2013.00095.x.

Lucero, D. M. (2011). Resiliency of Latino high school students: the impact of external and internal factor. Loyola Marymount University. Retrieved from http://gradworks. proquest.com/3487778.pdf \%0A\%0A.

Luthar, S. S., Cicchetti, D., \& Becker, B. (2000). The construct of resilience: a critical evaluation and guidelines for future work. Child Development, 71(3), 543-62. Retrieved from http://www.ncbi.nlm.nih. gov/pubmed/10953923.

Luther, S. S. (2006). Resiliency in development: A synthesis of research across five decades. (D. Ciachetti \& D. J. Cohen, Eds.) (2nd ed.). Hoboken, NJ: John Wiley \& Sons.

Macharia, R. W. (2011). Investigation on factors influencing academic self-concept and academic achievement among day secondary students in Githobokoini Division, Gatundu District. Kenyatta University.

Mampane, M. R. (2014). Factors contributing to the resilience of middle-adolescents in a South African township: Insights from a resilience questionnaire. South African Journal of Education, 34(4), 1-11. https://doi.org/10.15700/201412052114.

Martin, A. J., \& Marsh, H. W. (2006). Academic resilience and its psychological and educational correlates: A construct validity approach. Psychology in the Schools, 43(3), 267-281. https://doi. org/10.1002/pits.20149.

Masten, A. S., \& Reed, M. J. (2002). Resilience in development. (C. R. Snyder \& S. J. Lopez, Eds.). New York, NY: Oxford University Press.

Merdinger, J.M., Hines, A.M., Osterling, K.L. \& Wyatt, P. (2005). Pathways to college for former foster youth: Understanding factors that contribute to educational success. Child Welfare, Lxxxiv (6), 867-896.

Mehrotra, S., \& Chaddha, U. (2013). A corelational study of protective factors, resilience and self esteem in pre medical dropouts. International Journal of Humanities and Social Science Invention ISSN (Online, 2(9), 2319-7722. Retrieved from www.ijhssi.org.

Ministry of Education. (2008). Central province provincial stakeholders education conference awards day. Nyeri, Kenya.

Ministry of Education. (2009). Central province provincial stakeholders' education conference awards day. Nyeri, Kenya.

Morales, E. E. (2010). Linking strengths: Identifying and exploring protective factor cluster in academically resilient low-socioeconomic urban students of color. Roeper Review, 32, 164-175. Doi:10.1080/02783193.2010.485302.

Morrison, G. M., \& Allen, M. R. (2007). Promoting student resilience in school contexts. Theory into Practice, 46(2), 162-169. https://doi.org/10.1080/00405840701233172. 
Murugami, M. W. (2002). Effects of locus of control on self-concept among secondary school learners in special schools in Central Province. Kenyatta University.

Mwangi, C., Okatcha, F., Kinai, T., \& Ireri, A. (2015). Relationship between academic resilience and academic achievement among secondary school students in Kiambu County, Kenya. International Journal of School and Cognitive Psychology, 1(s2). https://doi.org/10.4172/2469-9837.S2-003.

Olamiju, D. J. (2013). An examination of at risk high school students' perceptions of the factors that foster resiliency in their suburban high school (Unpublished master's thesis).St. John Fisher College.

Oliwa, B. N. (1998). A study on the relationship between achievement motivation, locus of control and academic performance of class eight pupils in Bondo District. Kenyatta University.

Ratioran, S., \& Phlainoi, S. (2014). Promoting resilience in schoolchildren in urban slums. ASR: CMUJ of Social Sciences and Humanities, 1(1). https://doi.org/10.12982/cmujASR.2014.0005.

Rennie, C. E., \& Dolan, M. C. (2010). The significance of protective factors in the assessment of risk. Criminal Behaviour and Mental Health, 20(1), 8-22. https://doi.org/10.1002/cbm.750.

Republic of Kenya (2012). Ministry of Education task force on the re-alignment of the education sector to the Constitution of Kenya 2010: Towards a globally competitive quality education for sustainable development report of the task force. Nairobi, Author.

Rono, R. C. (1991). The effects of peer pressure on educational achievement, educational aspirations and occupational aspirations of form four students in Kericho District. Kenyatta University, Kenya.

Sanders, M. G. (1999). Schooling students placed at risk : research, policy, and practice in the education of poor and minority adolescents. L. Erlbaum Associates, Publishers.

Sandoval-Hernández, A., \& Białowolski, P. (2016). Factors and conditions promoting academic resilience: a TIMSS-based analysis of five Asian education systems. Asia Pacific Education Review, 17(3), 511-520. https://doi.org/10.1007/s12564-016-9447-4.

Sharkey, J. D., You, S., \& Schnoebelen, K. (2008). Relations among school assets, individual resilience, and student engagement for youth grouped by level of family functioning. Psychology in the Schools, 45(5). https://doi.org/10.1002/pits.20305.

Solberg, V.S.H., Close, W. \& Metz, A.J. (2002). Promoting success pathways for middle and High School students: Introducing the Adaptive Success Identity plan for school counselors. In C.L. Juntunen and D.R. Atkinson (Eds.), Counseling across the lifespan, pp. 135-157. Thousand Oaks, CA: sage.

The Kenya National Examinations Council, (KNEC). (2015). The 2015 Kenya Certificate of Secondary Education Essential Statistics. Nairobi, Kenya.

Theron, L.C., Theron, A.M.C., \& Malindi, M.J. (2013). Toward an African definition of resilience: A rural South African community's view of resilient Basotho youth. Journal of Black Psychology, 39(1) 63-87. doi: $10.1177 / 0095798412454675$.

Toland, J., \& Carrigan, D. (2011). Educational psychology and resilience: New concept, new opportunities. School Psychology International, 32, 95-106. http://dx.doi.org/10.1177/014303 4310397284

Schunk, D. H., \& Zimmerman, B. J. (2007). Influencing children's self-efficacy and self-regulation of reading and writing through modeling. Reading and Writing Quarterly, 23, 7-25.

Ungar, M. (2004). A constructionist discourse on resilience: Multiple contexts, multiple realities among atrisk children and youth. Youth \& Society, 35(3), 341-365. https://doi.org/10.1177/0044118X03257030.

Ungar, M., \& Liebenberg, L. (2011). Assessing resilience across cultures using mixed methods: Construction of the child and youth resilience measure. Journal of Mixed Methods Research, 5, 126-149. doi:10.1177/1558689811400607.

Wasonga, T., Christman, D.E., \& Kilmer, L. (2003). Ethnicity, gender and age: Predicting resilience and academic achievement among urban high school students. American Secondary Education, 32(1), 6274. Retrieved from http://www.jstor.org/stable/41064505.

Waxman, H. C., Padron, Y. N., \& Gray, J. P. (2004). Educational resiliency: Student, teacher, and school perspectives. (H. C. Waxman, Y. N. Padron, \& J. P. Gray, Eds.). California: Information Age.

Yamane, T. (1973). Statistics: An introductory analysis. Harper \& Row.

Yavuz, H.Ç., \& Kutlu, O. (2016). Investigation of the factors affecting the academic resilience of economically disadvantaged high school students. Education and Science, 41(186)1-19. 